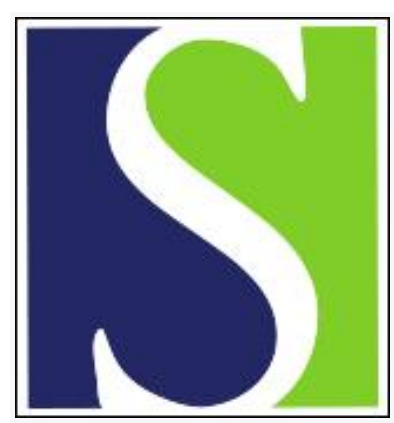

Scand J Work Environ Health 1986;12(6):609-613

https://doi.org/10.5271/sjweh.2095

Issue date: Dec 1986

Measurements of extremely low-frequency magnetic fields around video display terminals.

by Juutilainen J, Saali K

This article in PubMed: www.ncbi.nlm.nih.gov/pubmed/3823810

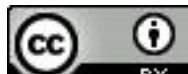




\title{
Measurements of extremely low-frequency magnetic fields around video display terminals
}

\author{
by Jukka Juutilainen, MSc, Keijo Saali, $\mathrm{MSc}^{1}$
}

\begin{abstract}
JUUTILAINEN J, SAALI K. Measurements of extremely low-frequency magnetic fields around video display terminals. Scand J Work Environ Health 12 (1986) 609-613. The extremely low-frequency (ELF) magnetic field emissions of seven video display terminal (VDT) models were measured. A measuring coil with a linearized frequency response $(50 \mathrm{~Hz}$ to $25 \mathrm{kHz})$ was used. The dominating ELF magnetic field around the terminals was the 50 or $60 \mathrm{~Hz}$ asymmetric triangular waveform from the vertical deflection coil of the cathode ray tube. At the distance of $50 \mathrm{~cm}$, the magnetic field strength was still slightly higher than the background level in usual office rooms, but several orders of magnitude lower than the thresholds of known interaction mechanisms. Some recent experiments suggest that certain biological effects may occur at field strengths only a few times higher than those found at the position of VDT operators, but the significance of these effects to human health is not known.
\end{abstract}

Key terms: cathode ray tube, biological effects, teratology.

The video display terminal (VDT) has, in recent years, become an essential part of almost every modern office. In response to public concerns about the possible health effects of these terminals, several studies have been carried out in order to determine their electromagnetic emissions $(8,13,16,23,26,27)$. All measurements from low-frequency electric fields to X-rays have shown that the emissions are far below any safety standards and known biological effects (2). However, only a few measurements of the extremely low-frequency (ELF) magnetic fields with frequencies below $1 \mathrm{kHz}$ in front of three VDT models have been published (22). ELF magnetic fields have been reported to affect chick embryogenesis $(4,10,11,25)$. Because questions have been raised about the effects of VDT exposure on pregnant women (see reference 2), it appeared necessary to study the magnetic fields around several VDT models. Measurements were made at all sides of the devices, and, in addition to the intensity of the magnetic field, also its waveform and polarization was determined.

It is not known at present which is the most relevant measure of low-frequency magnetic fields. Both amplitude $(\mathrm{H})$ and induction [rate of change of the magnetic field $(\mathrm{dH} / \mathrm{dt})$ ] have been used. The use of the latter is based on the assumption that the biological effects of magnetic fields are due to the electric currents induced in the exposed object. Because the rate of change of ELF magnetic fields is relatively low, the most important such emissions from a VDT are at very low frequencies (VLF) ie, $1 \mathrm{kHz}-100 \mathrm{kHz}$, and not in the ELF range. The VLF magnetic field emissions

\footnotetext{
1 Department of Environmental Hygiene, University of Kuopio, Finland.
}

Reprint requests to: Mr J Juutilainen, Department of Environmental Hygiene, University of Kuopio, POB 6, SF-70211, Kuopio, Finland. (both amplitude and rate of change) of several VDT models have been measured by Paulsson et al (20). Because the rate of change would be of minor importance at ELF in comparison to VLF, and certain suggested biological effects of ELF magnetic fields seem to be independent of the rate of change $(10,11,15)$, we chose to measure the amplitude $(\mathrm{H})$ of the magnetic field.

\section{Materials and methods}

The magnetic field was measured with a 500-turn coil having a diameter of $150 \mathrm{~mm}$. The output voltage of a measuring coil is proportional to the frequency (f) of the magnetic field. The frequency response of the coil was linearized by a low-pass filter with a frequency response proportional to $1 / \mathrm{f}$ above $50 \mathrm{~Hz}$ (figure 1). The coil was shielded against electric fields with an aluminum plate around the coil and copper foils on the sides of the coil. The shield also damped the selfresonance of the coil at about $25 \mathrm{kHz}$. The resulting frequency response is shown in figure 2 . The output of the coil was measured with a portable millivoltmeter with an input impedance of $100 \mathrm{M} \Omega$. The waveform of the measured field was monitored on an oscilloscope connected to the output of the coil.

The measuring coil was calibrated in a known magnetic field between square Helmholtz coils. The 10-turn

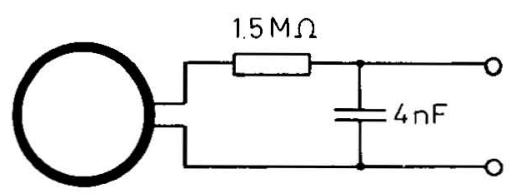

Figure 1. Schematic of the measuring coil. 


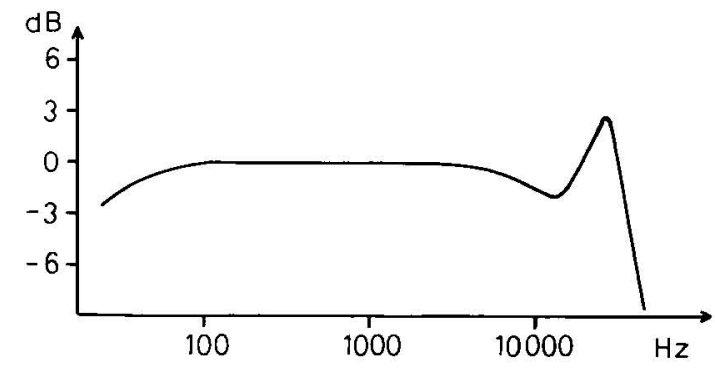

Figure 2. Frequency response of the measuring coil.

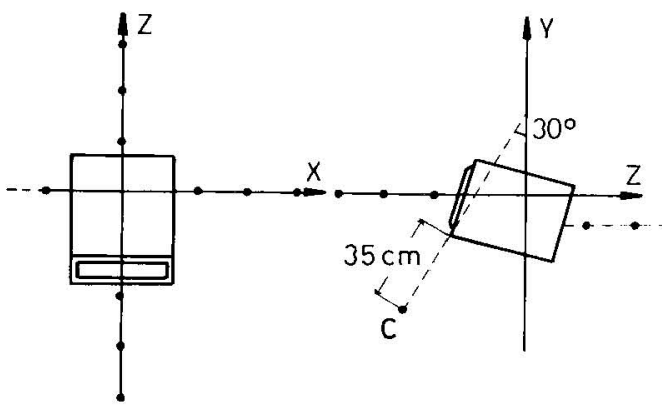

Figure 3. Location of the measurement points. coils had a size of $0.4 \times 0.4 \mathrm{~m}$ and a width of $15 \mathrm{~mm}$. The distance between the coils was $0.24 \mathrm{~m}$. The magnetic field strength between the calibrating coils was calculated with a computer program based on an analytical solution of the field equation derived from the Biot-Savart law (21). With a current of 1 A passing through the coil, the magnetic field strength between the coils was $30.5 \mathrm{~A} / \mathrm{m}$. The calibration was done with a triangular waveform similar to that used in the vertical deflection coil of a VDT cathode ray tube. In a field strength of $1 \mathrm{~A} / \mathrm{m}$ [root mean square (rms)], the measuring coil was found to give an output of $1.5 \mathrm{mV}$. This value is slightly less than the output voltage $(1.62 \mathrm{mV})$ obtained with a sinusoidal field of the same strength.

Measurements were made on all four sides of the terminals (figure 3 ). On each side, the location of the maximum field at the surface of the device was found, and measurements were taken at distances of 10,30 , and $50 \mathrm{~cm}$ from this point. An additional measurement was made at the operator's chair at the position approximated for the fetus if the operator were a pregnant woman (measurement point $\mathrm{C}$ in figure 3). By turning the coil to find the maximum reading, we determined the polarization of the field in relation to

Table 1. Low-frequency magnetic field strength $(\mathrm{A} / \mathrm{m})$ around the video display terminals. Background (power off) measurements are given in parentheses.

\begin{tabular}{|c|c|c|c|c|}
\hline \multirow{2}{*}{$\begin{array}{l}\text { Location of } \\
\text { measurement }\end{array}$} & \multicolumn{3}{|c|}{ Distance } & \multirow{2}{*}{$\begin{array}{l}\text { At operator's } \\
\text { chair, } 35 \mathrm{~cm}\end{array}$} \\
\hline & $10 \mathrm{~cm}$ & $30 \mathrm{~cm}$ & $50 \mathrm{~cm}$ & \\
\hline \multicolumn{5}{|c|}{ Data General D 211} \\
\hline $\begin{array}{l}\text { Front } \\
\text { Right side } \\
\text { Left side } \\
\text { Back }\end{array}$ & $\begin{array}{l}0.87 \\
2.5 \\
2.3 \\
1.8\end{array}$ & $\begin{array}{l}0.20 \\
0.45 \\
0.48 \\
0.09\end{array}$ & $\begin{array}{l}0.10(0.08) \\
0.22(0.05) \\
0.15(0.03) \\
0.05(0.03)\end{array}$ & $\begin{array}{c}0.13(0.04) \\
\vdots \\
\vdots\end{array}$ \\
\hline \multicolumn{5}{|c|}{ Hewlett-Packard $82913 \mathrm{~A}$} \\
\hline $\begin{array}{l}\text { Front } \\
\text { Right side } \\
\text { Left side }\end{array}$ & $\begin{array}{l}0.76 \\
1.3 \\
1.7\end{array}$ & $\begin{array}{l}0.24 \\
0.32 \\
0.37\end{array}$ & $\begin{array}{l}0.20(0.16) \\
0.18(0.15) \\
0.19(0.16)\end{array}$ & $\begin{array}{l}0.17(0.15) \\
\quad \\
.\end{array}$ \\
\hline \multicolumn{5}{|c|}{ Kaypro $16 / H D$} \\
\hline $\begin{array}{l}\text { Front } \\
\text { Right side } \\
\text { Left side }\end{array}$ & $\begin{array}{l}2.7 \\
1.5 \\
4.0\end{array}$ & $\begin{array}{l}0.35 \\
0.21 \\
0.65\end{array}$ & $\begin{array}{l}0.11(0.06) \\
0.18(0.02) \\
0.20(0.01)\end{array}$ & $\begin{array}{l}0.20(0.02) \\
\cdot\end{array}$ \\
\hline \multicolumn{5}{|l|}{ LSI ADM 32} \\
\hline $\begin{array}{l}\text { Front } \\
\text { Right side } \\
\text { Left side } \\
\text { Back }\end{array}$ & $\begin{array}{l}0.90 \\
1.2 \\
2.2 \\
1.5\end{array}$ & $\begin{array}{l}0.24 \\
0.25 \\
0.40 \\
0.25\end{array}$ & $\begin{array}{l}0.10(0.03) \\
0.10(0.03) \\
0.17(0.08) \\
0.10(0.03)\end{array}$ & $\begin{array}{l}0.15(0.03) \\
: \\
:\end{array}$ \\
\hline \multicolumn{5}{|c|}{ Nokia VDU 52} \\
\hline $\begin{array}{l}\text { Front } \\
\text { Right side } \\
\text { Left side } \\
\text { Back }\end{array}$ & $\begin{array}{l}0.91 \\
2.2 \\
2.3 \\
2.3\end{array}$ & $\begin{array}{l}0.22 \\
0.42 \\
0.40 \\
0.27\end{array}$ & $\begin{array}{l}0.09(0.02) \\
0.15(0.01) \\
0.15(0.07) \\
0.07(0.01)\end{array}$ & $\begin{array}{c}0.20(0.01) \\
\cdot \\
\cdot\end{array}$ \\
\hline \multicolumn{5}{|c|}{ Nokia VDU 202} \\
\hline $\begin{array}{l}\text { Front } \\
\text { Right side } \\
\text { Left side } \\
\text { Back }\end{array}$ & $\begin{array}{l}0.97 \\
3.7 \\
2.0 \\
3.3\end{array}$ & $\begin{array}{l}0.26 \\
0.53 \\
0.42 \\
0.43\end{array}$ & $\begin{array}{l}0.10(0.03) \\
0.23(0.03) \\
0.19(0.03) \\
0.15(0.03)\end{array}$ & $\begin{array}{c}0.31(0.07) \\
\vdots\end{array}$ \\
\hline \multicolumn{5}{|l|}{ Wyse WY 85} \\
\hline $\begin{array}{l}\text { Front } \\
\text { Right side } \\
\text { Left side } \\
\text { Back }\end{array}$ & $\begin{array}{l}0.91 \\
2.7 \\
3.1 \\
1.9\end{array}$ & $\begin{array}{l}0.31 \\
0.44 \\
0.53 \\
0.32\end{array}$ & $\begin{array}{l}0.07(0.01) \\
0.16(0.04) \\
0.17(0.03) \\
0.07(0.03)\end{array}$ & $\begin{array}{c}0.17(0.03) \\
\vdots \\
\end{array}$ \\
\hline
\end{tabular}


the coordinates $(x, y, z)$ shown in figure 3 . The measurements were made on wooden tables in usual office rooms. The background magnetic fields in each room were measured while the VDT was turned off.

The accuracy of the measuring and calibration system was estimated to be better than $5 \%$, but the uncertainty in the position of the measuring coil during measurements introduced an error of about $10-20 \%$.

\section{Results}

The magnetic field strengths of different VDT models were similar (table 1). At a distance of $30 \mathrm{~cm}$ from the terminal, the field strength varied from 0.2 to 0.35 $\mathrm{A} / \mathrm{m}$ (rms). There were regular variations with a period of a few seconds in the field strengths of the two Nokia terminals. For these, the maximum values are reported. The strongest fields (up to $4 \mathrm{~A} / \mathrm{m}$ ) were found near the left and right sides of the terminal, and at the backside of some devices. The field appeared to decrease rapidly with increasing distance. At a distance of $50 \mathrm{~cm}$, the field strength varied from 0.05 to $0.22 \mathrm{~A} / \mathrm{m}$. These figures are much higher than the natural background of about $10^{-6} \mathrm{~A} / \mathrm{m}$ (28), but they are only slightly higher than the usual office background caused by various electrical appliances. The highest value measured at the chair of the operator was $0.31 \mathrm{~A} / \mathrm{m}$. The highest values were measured around the Kaypro 16/HD device, which is actually a combination of a visual display and a microcomputer equipped with a hard disk unit. However, the location of the maximum fields showed that the main ELF magnetic field source of this device, as well as of the usual VDT models, was the cathode ray tube.

In addition to the measurements reported in table 1 , measurements were made at all sides of some terminals. An example of these measurements is shown in figure 4 . The polarization of the field was always the same, the magnetic field lines of force being parallel to the $\mathrm{x}$-axis shown in figure 3 .

The dominating waveform near the terminals appeared to be similar to that used in the vertical deflection coil of the cathode ray tube. The frequency of this signal was $60 \mathrm{~Hz}$ in some of the devices and $50 \mathrm{~Hz}$ in the others. A signal with a frequency near $20 \mathrm{kHz}$ from the horizontal deflection system was also present. The strength of this signal varied, but it was clearly weaker than the 50 or $60 \mathrm{~Hz}$ signal in all the models. The measured waveforms shown in figure 5 are somewhat deformed because the frequency of the signal was near the low-frequency limit of the measuring coil. The actual waveform is triangular with a fast rising phase and a slow falling phase (or slow rising and fast falling phase, depending on how the polarity is chosen). Sinusoidal $50-\mathrm{Hz}$ fields could also be measured near the power transformer of some of the terminals. However, these fields were limited to the immediate vicinity of the power transformer, and the previously de-

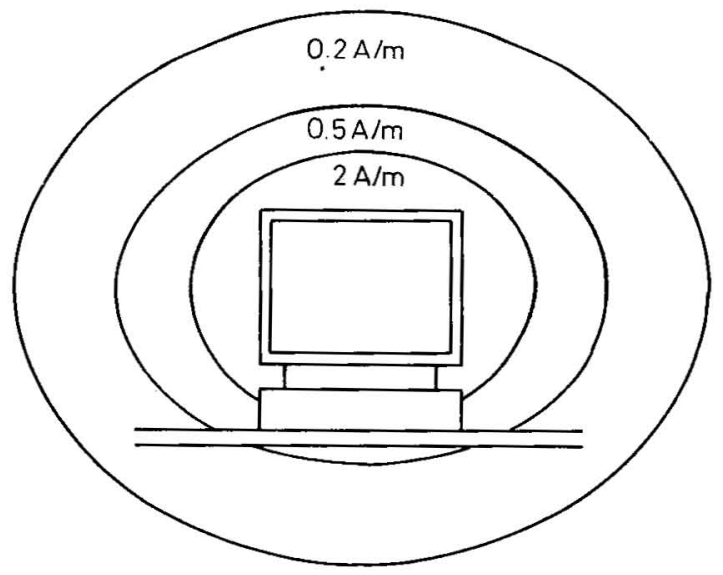

Figure 4. Extremely low-frequency magnetic field distribution around a video display terminal.

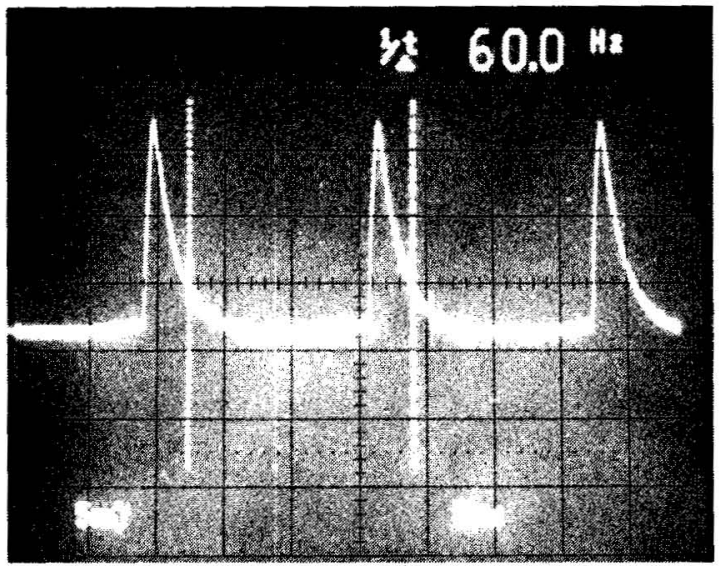

Figure 5. Waveform of the extremely low-frequency magnetic field near a video display terminal.

scribed triangular waveform was dominant at all other locations.

\section{Discussion}

The location, polarization, waveform, and frequency of the measured magnetic fields showed that the most important source of ELF magnetic fields in a VDT is the vertical deflection coil of the cathode ray tube. A magnetic deflection system is used in the tubes with a large deflection angle. This kind of cathode ray tube is usual, eg, in visual display terminals and television sets. The magnetic deflection system consists of two rectangular coils at both sides of the neck of the cathode ray tube. The most important factor determining the field strength near the VDT seemed to be the external dimensions of the device. At the distance of $10 \mathrm{~cm}$, the strongest fields were measured around small devices, ie, when the measurement point was near the deflection coils. 
No generally accepted exposure limits or emission standards exist for low-frequency magnetic fields $(9$, 28 ). The only well-known interaction mechanism for low-frequency magnetic fields is the induction of electric currents in biological tissues. The induced currents are proportional to the rate of change of the magnetic field $(\mathrm{dH} / \mathrm{dt})$. At $1 \mathrm{~A} / \mathrm{m}$, the maximum rate of change of the magnetic field of the ELF waveform used in the vertical deflection coil is about $4 \cdot 10^{3} \mathrm{~A} / \mathrm{ms}$. Theoretical (3) and empirical (19) thresholds for biological effects are several orders of magnitude more than this figure. It should be noticed that although the amplitude $(H)$ of the VLF signals from the horizontal deflection coils is low, the rate of change of the magnetic field can be up to $10^{5} \mathrm{~A} / \mathrm{ms}(20)$.

Some biological experiments suggest that ELF magnetic fields with a relatively low intensity have certain biological effects $(1,5,7,15)$. At least some of these effects seem to be independent of the rate of change of the magnetic field and therefore indicate that the interaction mechanism is something other than the induction of electric currents $(10,11,15)$. The significance of these effects to human health is not known. Furthermore, the relationship between the effects and field strength is not known. Our experiments with chick embryos suggest that the minimum field strength required to disturb embryonal development is near 1 $\mathrm{A} / \mathrm{m}$ rms (10). The lowest field strength found effective in stimulating the thymidine uptake of cultured human fibroblasts was about $1.3 \mathrm{~A} / \mathrm{m}$ (15). Field strengths of more than $1 \mathrm{~A} / \mathrm{m}$ were measured only at a distance of $10 \mathrm{~cm}$ from the VDT. At $50 \mathrm{~cm}$, the field strength was usually below $0.2 \mathrm{~A} / \mathrm{m}$. A waveform similar to that produced by a VDT has not been used in biological experiments. However, sinusoidal, square, and pulsed waveforms appear to have quite similar effects $(10)$. Therefore the waveform is probably not critical although small differences in the effectivity of various waveforms are possible.

As the biophysical mechanism of the effects of the ELF magnetic field on chick embryos is not known, it is not possible to conclude whether similar effects could be expected in human beings. Several recent epidemiologic studies suggest that work with a VDT has no adverse effects on pregnancy outcome (24). In a case-referent study of 2950 mothers, no association between VDT exposure and birth defects was found (14). Neither did the results of two Swedish investigations suggest a teratogenetic risk for VDT operators $(6,12)$. The rate of spontaneous abortion among VDT operators was reported to be increased in the preliminary results of one study (18). However, this finding may be explained by error due to selection bias, and the authors have later concluded that VDT exposure has no adverse effect on the outcome of pregnancy (17).

In conclusion, the ELF magnetic fields around a VDT are not hazardous to human health according to present knowledge. However, several biological ex- periments suggest that also weak magnetic fields may have biological effects with unknown mechanisms. Additional biological experiments are necessary to confirm the suggested effects and to find the mechanisms and dose-response relationships of these effects.

\section{References}

1. Aarholt E, Flinn EA, Smith CW. Effects of lowfrequency magnetic fields on bacterial growth rate. Phys Med Biol 26 (1981) 613-621.

2. Bergqvist UOV. Video display terminals and health: $\mathrm{A}$ technical and medical appraisal of the state of the art. Scand J Work Environ Health 10 (1984) suppl 2, 87p.

3. Bernhardt $\mathbf{J}$. The direct influence of electromagnetic fields on nerve and muscle cells of man within the frequency range of $1 \mathrm{~Hz}$ to $30 \mathrm{MHz}$. Radiat Environ Biophys 16 (1979) 309-323.

4. Delgado JMR, Leal J, Monteagudo JL, Garcia Gracia M. Embryological changes induced by weak, extremely low frequency electromagnetic fields. J Anat 134 (1982) $533-551$.

5. Dihel LE, Smith-Sonneborn J, Middaugh CR. Effects of extremely low frequency magnetic fields on the cell division rate and plasma membrane of Paramecium tetraurelia. Bioelectromagnetics 6 (1985) 61-71.

6. Ericson A, Källen B, Westerholm P. Försäkringskassestudien: Ingen ökad risk för fosterskador hos kvinnor med bildskärmarbete. Läkartidningen 82 (1985) 21802184.

7. Greenebaum B, Goodman EM, Marron HT. Magnetic field effects on mitotic cycle length in Physarum. Eur J Cell Biol 27 (1982) 156-160.

8. Harvey SM. Electric-field exposure of persons using video display units. Bioelectromagnetics 5 (1984) $1-12$.

9. International Labour Office. Occupational hazards from nonionizing electromagnetic radiation. Geneva 1985. (Occupational safety and health series no 53).

10. Juutilainen J, Harri M, Saali K, Lahtinen T. Effects of $100-\mathrm{Hz}$ magnetic fields with various waveforms on the development of chick embryos. Radiat Environ Biophys 25 (1986) 65-74.

11. Juutilainen J, Saali K. Development of chick embryos in $1 \mathrm{~Hz}$ to $100 \mathrm{kHz}$ magnetic fields. Radiat Environ Biophys 25 (1986) 135-140.

12. Källen B. Dataskärmsarbete och graviditet. Läkartidningen 82 (1985) 1339-1342.

13. Knave BG, Wilbom RI, Bergqvist UOV, Carlsson LLW, Levin MIB, Nylen PR. Work with video display terminals among office employees: II Physical exposure factors. Scand J Work Environ Health 11 (1985) 467-474.

14. Kurppa K, Holmberg PC, Rantala K, Nurminen T, Saxen $\mathrm{L}$. Birth defects and exposure to video display terminals during pregnancy: A Finnish case-referent study. Scand J Work Environ Health 11 (1985) 353-356.

15. Liboff AR, Williams T, Strong DM, Wistar R. Timevarying magnetic fields: Effect on DNA-synthesis. Science 223 (1984) 818-820.

16. Marha K, Charron D. The distribution of a pulsed very low frequency electric field around video display terminals. Health Physics 49 (1985) 517-521.

17. McDonald A. Birth defect, spontaneous abortion and work with VDUs. In: Swedish National Board of Occupational Safety and Health. Proceedings of the international conference: Work with display units, Stockholm, May 12-15 1986. Stockholm 1986, pp 669-670.

18. McDonald AD, Cherry NM, Commandeur C, Delorme D, Lavoie J, Marquis S. Work and pregnancy in Montreal - Preliminary findings. Scand J Work Environ Health 10 (1984) 132. (Abstract). 
19. McRobbie D, Foster MA. Thresholds for biological effects of time-varying magnetic fields. Clin Phys Physiol Meas 5 (1984) 67-78.

20. Paulsson L-E, Kristiansson I, Malmström I. Strålning från dataskärmar. Statens strålskyddsinstitut, Stockholm 1984.

21. Saali K, Juutilainen J, Lahtinen T. A system for exposing biological objects to variable combinations of electric and magnetic fields. Med Biol Eng Comput 23 (1985): suppl part 2, 854.

22. Stuchly MA, Lecuyer DW, Mann RD. Extremely low frequency electromagnetic emissions from video display terminals and other devices. Health Physics 45 (1983) 713-722.

23. Stuchly MA, Repacholi MH, Lecuyer DW, Mann RD. Radiofrequency emissions from video display terminals. Health Physics 45 (1983) 772-775.

24. Swedish National Board of Occupational Safety and Health. Proceedings of the international scientific conference: Work with display units, Stockholm, May
12-15 1986. Stockholm 1986.

25. Ubeda A, Leal J, Trillo MA, Jimenez MA, Delgado JMR. Pulse shape of magnetic fields influences chick embryogenesis. J Anat 137 (1983) 513-536.

26. Weiss MM. The video display terminals - Is there a radiation hazard? J Occup Med 25 (1983) 98-101.

27. Wolbarsht ML, O'Foghludha FA, Sliney DH, Guy AW, Smith AA, Johnson GA. Electromagnetic emissions from video display units: A non-hazard. In: Nonionizing radiation, proceedings of a topical symposium, Nov 26-28 1979, Washington DC. American Conference of Governmental Industrial Hygienists, Cincinnati $\mathrm{OH}$ 1980, pp 193-201.

28. World Health Organization. Extremely low frequency electromagnetic fields. Geneva 1981. (Environmental health criteria 35 ).

Received for publication: 20 March 1986 